\title{
PROJETOS E PROGRAMAS SOCIAIS ESPORTIVOS NO BRASIL: UMA REVISÃO SISTEMÁTICA
}

SPORT SOCIAL PROGRAMS AND PROJECTS IN BRAZIL:

A SYSTEMATIC REVIEW

PROYECTOS Y PROGRAMAS SOCIALES DEPORTIVOS EN BRASIL: UNA REVISIÓN SISTEMÁTICA

Claudio Kravchychyn*, Amauri Aparecido Bássoli de Oliveira*

Palavras chave:

Esportes.

Projetos de

investimento social.

Revisão.
Resumo: A revisão sistemática qualitativa objetivou apresentar o estado da arte de projetos e programas sociais esportivos no Brasil a partir da produção científica sobre o tema, publicada em periódicos científicos da área da Educação Física. As buscas realizaram-se nas bases de dados Lilacs, Scielo, Latindex, Portal de Periódicos da Capes e Biblioteca Virtual em Saúde. Aplicados os critérios de inclusão e exclusão, dos 50 estudos identificados inicialmente, 28 foram selecionados. Concluiu-se que os dados obtidos podem referenciar futuras pesquisas sobre o tema e ações de gestão e desenvolvimento pedagógico nesse contexto.

\section{Keywords:}

Sports.

Social Investment

Projects.

Systematic Review.
Abstract: This qualitative systematic review aimed at presenting the current status of sport social projects and programs in Brazil based on scientific production on the topic published on Physical Education journals. Searches were conducted on Lilacs, Scielo, Latindex, Portal de Periódicos da Capes e Biblioteca Virtual em Saúde. After applying inclusion and exclusion criteria, 28 out of 50 studies were selected. Data obtained can provide references to future studies about the subject and actions for management and pedagogical development in the context.
Palabras clave: Deportes.

Proyectos de inversión Social Revisión.
Resumen: La revisión sistemática cualitativa tuvo por objetivo presentar el estado del arte de proyectos y programas sociales deportivos en Brasil a partir de la producción cientíica sobre el tema, publicada en periódicos científicos del área de la Educación Física. Las búsquedas se realizaron en las bases de datos Lilacs, Scielo, Latindex, Portal de Periódicos Capes y Biblioteca Virtual en Salud. Aplicados los criterios de inclusión y exclusión, de los 50 estudios identificados inicialmente, 28 fueron seleccionados. Se concluyó que los datos obtenidos pueden endosar futuras investigaciones sobre el tema y acciones de gestión y desarrollo pedagógico en ese contexto.
*Universidade Estadual de Maringá. Maringá, Paraná, Brasil. E-mail: claudiokrav@gmail.com

Recebido em: 06-03-2015 Aprovado em: 11-07-2015 (c) (1) (8) Licence 


\section{INTRODUÇÃOO}

Os projetos e programas sociais esportivos (PPSE) ${ }^{1}$ integram o contexto das políticas públicas de esporte no Brasil desde a década de 1980 (ZALUAR, 1994). Mediante o crescimento da demanda, tais iniciativas despertaram o interesse científico-acadêmico da área da Educação Física, especialmente nos últimos dez anos.

NaproduçãocientíficasobrePPSE, posiçõesapologistas baseiam-senodesenvolvimento de valores e atitudes positivas, socialização, cidadania e combate à vulnerabilidade social infanto-juvenil, enquanto as críticas entendem tais iniciativas como produtos de um modelo governamental neoliberal, que repassa à sociedade civil responsabilidades do Estado (SOUZA et al., 2010; SOUZA; CASTRO; MEZZADRI, 2012).

Entretanto, evidencia-se uma terceira e já predominante demanda de pesquisa, que prioriza questões pedagógicas, socioculturais e administrativas dos PPSE. Segundo Stigger e Thomassim (2013, p. 3),

[...] para a Educação Física, que possui sua identidade acadêmica associada à intervenção social, se coloca potencialmente uma dupla relação com este fenômeno: como objeto de estudo e de intervenção. Assim, não são poucos os professores, estudantes e pesquisadores que se colocam diante do desafio de buscar compatibilizar a análise crítica dos processos e dinâmicas sociais que condicionam e envolvem os projetos sociais, com proposições ou referências para a atuação pedagógica direta nestes espaços.

Considerando a expansão dos PPSE no Brasil e o interesse da comunidade científica, questiona-se: que abordagens, resultados e direcionamentos são apresentados pela produção científica, com vistas à pesquisa e à intervenção profissional no contexto pesquisado?

O estudo objetivou, portanto, apresentar o estado da arte ${ }^{2}$ de PPSE brasileiros a partir da produção científica sobre o tema, publicada em periódicos científicos da área da Educação Física.

\section{MÉTODO}

Diante da predominância de pesquisas qualitativas sobre PPSE, utilizou-se um processo de revisão sistemática qualitativa, uma síntese de pesquisas relacionadas à questão norteadora envolvendo a interpretação de dados organizados, considerando similaridades e diferenças entre os estudos e buscando ampliar as possibilidades interpretativas dos resultados, apontar possíveis lacunas e direcionamentos sobre o objeto estudado e construir (re)leituras ampliadas (GOMES; CAMINHA, 2014).

Conforme preconizado por De-La-Torre-Ugarte-Guanilo, Takahashi e Bertolozzi (2011), dois pesquisadores, de forma independente, buscaram, avaliaram e selecionaram os estudos, considerando as validades descritiva (identificação de estudos relevantes), interpretativa (correspondência entre o registrado pelo pesquisador e o conteúdo), teórica (credibilidade dos métodos) e pragmática (aplicabilidade do conhecimento).

1 Referência a programas e projetos sociais que têm o esporte como eixo norteador. Neste estudo utilizamos a denominação "sociais esportivos" por ser a mais constante na literatura. Conceitualmente, há similaridade a denominações, tais como projetos socioeducacionais mediante o esporte (VIANNA; LOVISOLO, 2009a), socioeducativos por meio do esporte (SOUZA et al., 2010) e socioesportivos (TUBINO, 2010). No Brasil, essas iniciativas são geralmente constituídas mediante políticas sociais governamentais (esferas federal, estadual e municipal), iniciativa privada e organizações sem fins lucrativos e/ou não governamentais (ONGs). 
A busca foi efetuada nas bases eletrônicas Lilacs (www.lilacs.bvsalud.org), Biblioteca Virtual em Saúde (www.bireme.br), Scielo (www.scielo.org), Latindex (www.latindex.unam.mx) e Periódicos Capes (www.periodicos.capes.gov.br), sob os descritores: "projeto social", "programa social", "educação", "educacional", "infância", "criança", "adolescência", "adolescente", "juventude" e "jovem", termos ligados diretamente ao tema; e "cidadania", "inclusão social", "vulnerabilidade social" e "risco social", observados nas leituras prévias como termos constantemente utilizados na composição de objetivos de PPSE, combinados com "esporte", "desporto" e "Brasil" e consultados nos idiomas português, inglês e espanhol. A seleção dos estudos baseou-se em critérios de inclusão e exclusão, definidos consensualmente pelos pesquisadores.

Critérios de inclusão: a) artigos sobre PPSE brasileiros, publicados em periódicos com classificação mínima B4 no Webqualis/Capes/Educação Física; (www.qualis.capes.gov.br) 3; b) estudos relacionados a PPSE brasileiros, considerando suas estruturas sociais, políticas, administrativas e pedagógicas.

Critérios de exclusão: a) artigos de revisão; b) estudos realizados em PPSE brasileiros utilizando suas estruturas e/ou atores, mas que desconsideram tal contexto nos resultados e/ ou discussões; c) estudos realizados em PPSE não contemplando as faixas etárias de infância, adolescência e juventude.

A seleção dos artigos ocorreu entre abril e junho de 2014. Considerando a recência da temática, descartou-se a limitação temporal, usual em investigações similares.

Sob os critérios de inclusão, foram encontrados 50 artigos, publicados entre 2004 e 2013. Aplicados os critérios de exclusão, 22 foram descartados, 16 pelo critério "a" e seis pelo critério "b". A utilização do critério "c" foi inibida pela confirmação da hipótese de que a denominação PPSE é utilizada no meio científico brasileiro denotando ações voltadas à infância, adolescência e juventude.

A sinopse dos 28 artigos selecionados (Quadro 1) apresenta a seguinte composição: autor(es) e ano de publicação; título; objetivo geral; tipo de pesquisa, tipo de análise e abordagem teórica; amostra e denominação do projeto ou programa; e principais resultados. Tal síntese suscitou, para fins de análise, o estabelecimento das categorias "gestão", "conteúdos e métodos de ensino" e "formação e intervenção profissional" (Tabela 1), considerando objetivos, aspectos apresentados no desenvolvimento das pesquisas e seus principais resultados.

\section{RESULTADOS E DISCUSSÃO}

O Quadro 1 sintetiza os artigos selecionados, publicados entre 2004 e 2013.

Quadro 1 - Sinopse dos artigos originais sobre PPSE no Brasil (2004-2013)

\begin{tabular}{|c|c|c|c|c|c|}
\hline $\begin{array}{c}\text { Autores } \\
\text { (Ano) }\end{array}$ & Título & $\begin{array}{l}\text { Objetivo do } \\
\text { Estudo }\end{array}$ & $\begin{array}{l}\text { Pesquisa (tipo) / } \\
\text { Análise (tipo) / } \\
\text { Abordagem } \\
\text { Teórica }\end{array}$ & $\begin{array}{l}\text { Amostra / } \\
\text { Projeto ou } \\
\text { Programa }\end{array}$ & Principais resultados \\
\hline \multirow{3}{*}{$\begin{array}{c}\text { Molina, Silva } \\
\text { e Silveira }\end{array}$} & \multirow{3}{*}{$\begin{array}{l}\text { Celebração e } \\
\text { transgressão: a } \\
\text { representação } \\
\text { do esporte na } \\
\text { adolescência. }\end{array}$} & \multirow{3}{*}{$\begin{array}{l}\text { Compreender } \\
\text { a colaboração } \\
\text { das práticas nas } \\
\text { representações } \\
\text { dos alunos. }\end{array}$} & Descritiva & \multirow{2}{*}{$\begin{array}{c}20 \text { atores } \\
\text { (monitores e } \\
\text { alunos) }\end{array}$} & \multirow{3}{*}{$\begin{array}{l}\text { Esporte entendido como } \\
\text { brincadeira, saúde como } \\
\text { higiene e educação como } \\
\text { obediência, apresentando } \\
\text { consensos e contradições às } \\
\text { diretrizes do projeto. }\end{array}$} \\
\hline & & & Qualitativa & & \\
\hline & & & $\begin{array}{l}\text { Representação } \\
\text { social do sujeito } \\
\text { (FOUCAULT) }\end{array}$ & Não identificado & \\
\hline
\end{tabular}

3 Critério empírico, adotado consensualmente pelos pesquisadores. 
Continuação do quadro 1.

\begin{tabular}{|c|c|c|c|c|c|}
\hline $\begin{array}{l}\text { Autores } \\
\text { (Ano) }\end{array}$ & Título & $\begin{array}{l}\text { Objetivo do } \\
\text { Estudo }\end{array}$ & $\begin{array}{l}\text { Pesquisa (tipo) / } \\
\text { Análise (tipo)/ } \\
\text { Abordagem } \\
\text { Teórica }\end{array}$ & $\begin{array}{l}\text { Amostra / } \\
\text { Projeto ou } \\
\text { Programa }\end{array}$ & Principais resultados \\
\hline \multirow{3}{*}{$\begin{array}{l}\text { Melo } \\
\text { (2005) }\end{array}$} & \multirow{3}{*}{$\begin{array}{l}\text { A Vila Olímpica da Maré } \\
\text { e as políticas públicas } \\
\text { de esporte no Rio de } \\
\text { Janeiro: um debate } \\
\text { sobre a relação lazer, } \\
\text { esporte e escola. }\end{array}$} & \multirow{3}{*}{$\begin{array}{l}\text { Discutir a interação } \\
\text { entre o projeto e } \\
\text { as escolas. }\end{array}$} & Descritiva & \multirow{2}{*}{$\begin{array}{l}\text { Gestores (N não } \\
\text { especificado) }\end{array}$} & \multirow{3}{*}{$\begin{array}{c}\text { Superestimação de } \\
\text { beneficiados; dificuldades } \\
\text { pedagógicas; carência de } \\
\text { intervenções que potencializem } \\
\text { um processo educacional } \\
\text { crítico e criativo. }\end{array}$} \\
\hline & & & Qualitativa & & \\
\hline & & & $\begin{array}{l}\text { Marxista, mediada } \\
\text { pelas formulações } \\
\text { de Gramsci }\end{array}$ & $\begin{array}{l}\text { Vila Olímpica } \\
\text { Maré (RJ) }\end{array}$ & \\
\hline \multirow{3}{*}{$\begin{array}{l}\text { Dória e } \\
\text { Tubino }\end{array}$} & \multirow{3}{*}{$\begin{array}{l}\text { Avaliação da busca da } \\
\text { cidadania pelo Projeto } \\
\text { Olímpico da Mangueira }\end{array}$} & \multirow{3}{*}{$\begin{array}{l}\text { Verificar o alcance } \\
\text { de metas em } 15 \\
\text { anos de projeto. }\end{array}$} & Descritiva & \multirow{2}{*}{83 egressos } & \multirow{3}{*}{$\begin{array}{l}\text { As práticas mostraram-se } \\
\text { capazes de instrumentalizar } \\
\text { a construção da cidadania, } \\
\text { evidenciando amplo alcance } \\
\text { social. }\end{array}$} \\
\hline & & & Quali-quantitativa & & \\
\hline & & & Não priorizada & $\begin{array}{l}\text { Vila Olímpica da } \\
\text { Mangueira (RJ) }\end{array}$ & \\
\hline \multirow{3}{*}{$\begin{array}{l}\text { Machado } \\
\text { et al. } \\
(2007)\end{array}$} & \multirow{3}{*}{$\begin{array}{l}\text { O impacto de um } \\
\text { projeto de educação } \\
\text { pelo esporte no } \\
\text { desenvolvimento infantil. }\end{array}$} & \multirow{3}{*}{$\begin{array}{l}\text { Avaliar o impacto } \\
\text { do projeto } \\
\text { (desempenho } \\
\text { escolar, stress, } \\
\text { qualidade de vida } \\
\text { e atitudes). }\end{array}$} & $\begin{array}{c}\text { Quase } \\
\text { Experimental }\end{array}$ & 39 alunos & \multirow{3}{*}{$\begin{array}{c}\text { Pré e pós-teste. Sem } \\
\text { diferenças significativas } \\
\text { entre os grupos (participante/ } \\
\text { controle). Melhora no } \\
\text { desempenho escolar e nos } \\
\text { níveis de stress; piora na } \\
\text { percepção de qualidade de } \\
\text { vida. Atividades mostram-se } \\
\text { educativas e socializadoras. }\end{array}$} \\
\hline & & & Quanti-qualitativa & & \\
\hline & & & $\begin{array}{l}\text { Quatro Pilares da } \\
\text { Educação } \\
\text { (DELORS) }\end{array}$ & $\begin{array}{l}\text { Quero-Quero } \\
\text { - Porto Alegre } \\
\text { (RS) }\end{array}$ & \\
\hline \multirow{3}{*}{$\begin{array}{l}\text { Mello, } \\
\text { Ferreira Neto } \\
\text { e Votre }\end{array}$} & \multirow{3}{*}{$\begin{array}{l}\text { Intervenção da } \\
\text { Educação Física } \\
\text { em projetos sociais: } \\
\text { uma experiência de } \\
\text { cidadania e esporte em } \\
\text { Vila Velha (ES). }\end{array}$} & \multirow{3}{*}{$\begin{array}{l}\text { Analisar a } \\
\text { intervenção, } \\
\text { considerando } \\
\text { a relação } \\
\text { beneficiados- } \\
\text { atividades. }\end{array}$} & Descritiva & \multirow{2}{*}{$\begin{array}{c}83 \text { alunos } \\
\text { (evadidos e } \\
\text { participantes) }\end{array}$} & \multirow{3}{*}{$\begin{array}{l}\text { Valoriza-se apropriação de } \\
\text { técnicas, participação em } \\
\text { competições e socialização. } \\
\text { Considerar a relação sujeitos- } \\
\text { saberes possibilita conduzir } \\
\text { as práticas na perspectiva dos } \\
\text { participantes. }\end{array}$} \\
\hline & & & Qualitativa & & \\
\hline & & & $\begin{array}{l}\text { Da relação com o } \\
\text { Saber (CHARLOT) }\end{array}$ & $\begin{array}{l}\text { Esporte Cidadão } \\
\text { (ES) }\end{array}$ & \\
\hline \multirow{3}{*}{$\begin{array}{l}\text { Vianna e } \\
\text { Lovisolo }\end{array}$} & \multirow{3}{*}{$\begin{array}{l}\text { Projetos de inclusão } \\
\text { social através do } \\
\text { esporte: notas sobre a } \\
\text { avaliação. }\end{array}$} & \multirow{3}{*}{$\begin{array}{c}\text { Analisar e } \\
\text { discutir dados } \\
\text { administrativos do } \\
\text { projeto. }\end{array}$} & Descritiva & $\begin{array}{c}\text { Não } \\
\text { especificada }\end{array}$ & \multirow{3}{*}{$\begin{array}{l}\text { Participação, adesão, evasão } \\
\text { e exploração das modalidades } \\
\text { pelos participantes são } \\
\text { importantes variáveis na } \\
\text { avaliação do projeto. }\end{array}$} \\
\hline & & & Quali-quantitativa & \multirow{2}{*}{$\begin{array}{c}\text { Projeto de } \\
\text { Inclusão Social- } \\
\text { PIS (RJ) }\end{array}$} & \\
\hline & & & Não priorizada & & \\
\hline \multirow{3}{*}{$\begin{array}{l}\text { Vianna e } \\
\text { Lovisolo }\end{array}$} & \multirow{3}{*}{$\begin{array}{l}\text { Desvalorização da } \\
\text { aprendizagem técnica } \\
\text { na Educação Física: } \\
\text { evidências e críticas. }\end{array}$} & \multirow{3}{*}{$\begin{array}{l}\text { Conhecer as } \\
\text { aspirações dos } \\
\text { participantes } \\
\text { quanto à prática. }\end{array}$} & Descritiva & 77 alunos & \multirow{3}{*}{$\begin{array}{l}\text { Tornar-se atleta ou professor } \\
\text { povoa o imaginário dos alunos; } \\
\text { o não ensino da técnica parece } \\
\text { contrariar suas expectativas. }\end{array}$} \\
\hline & & & Quali-quantitativa & Projeto de & \\
\hline & & & Não priorizada & $\begin{array}{c}\text { Inclusão Social- } \\
\text { PIS (RJ) }\end{array}$ & \\
\hline \multirow{3}{*}{$\begin{array}{l}\text { Lazzari, } \\
\text { Thomassim e } \\
\text { Stigger }\end{array}$} & \multirow{3}{*}{$\begin{array}{l}\text { A socialização de } \\
\text { crianças e adolescentes } \\
\text { no contexto de um } \\
\text { projeto social de tênis. }\end{array}$} & \multirow{3}{*}{$\begin{array}{l}\text { Compreender } \\
\text { a influência da } \\
\text { participação na } \\
\text { socialização dos } \\
\text { participantes. }\end{array}$} & Descritiva & Alunos & \multirow{3}{*}{$\begin{array}{l}\text { Valor educativo das atividades } \\
\text { verificado pela coparticipação. } \\
\text { A incorporação de condutas } \\
\text { e valores exige interação com } \\
\text { diferentes contextos. }\end{array}$} \\
\hline & & & Qualitativa & $\begin{array}{c}\text { (N não } \\
\text { especificado) }\end{array}$ & \\
\hline & & & $\begin{array}{l}\text { Perspectiva } \\
\text { Antropológica } \\
\text { (WINKIN) }\end{array}$ & $\begin{array}{c}\text { Não } \\
\text { Identificado }\end{array}$ & \\
\hline & & & Descritiva & 14 integrantes & A participacão da universidade. \\
\hline Mattos et al. & $\begin{array}{l}\text { O esporte náutico e } \\
\text { a dinâmica da hélice }\end{array}$ & $\begin{array}{l}\text { Refletir sobre } \\
\text { o papel do } \\
\text { esporte no }\end{array}$ & Qualitativa & $\begin{array}{l}\text { (alunos; } \\
\text { instrutores; } \\
\text { técnicos) }\end{array}$ & $\begin{array}{l}\text { indústria e governo no projeto } \\
\text { são analisadas. Prefeitura de } \\
\text { Niterói é a principal parceria, }\end{array}$ \\
\hline (2010) & $\begin{array}{l}\text { triplice no Projeto Grael: } \\
\text { um estudo de caso. }\end{array}$ & $\begin{array}{l}\text { desenvolvimento } \\
\text { regional. }\end{array}$ & $\begin{array}{l}\text { Hélice Tríplice } \\
\text { (ETZKOWITZ; } \\
\text { ZHOU) }\end{array}$ & $\begin{array}{l}\text { Projeto Grael } \\
\text { (RJ) }\end{array}$ & $\begin{array}{l}\text { indústrias restringem-se ao } \\
\text { patrocínio e a universidade } \\
\text { local participa de forma tímida. }\end{array}$ \\
\hline & & & Descritiva & Alunos (N não & \\
\hline & & & Qualitativa & especificado) & $\begin{array}{l}\text { O projeto propicia aprendizado } \\
\text { esportivo e inibicão de }\end{array}$ \\
\hline Monteiro & $\begin{array}{l}\text { Projeto Segundo } \\
\text { Tempo: o Fanzine e a } \\
\text { leitura do esporte em } \\
\text { bairros violentos. }\end{array}$ & $\begin{array}{l}\text { Analisar o } \\
\text { cotidiano e a } \\
\text { história de vida } \\
\text { dos alunos. }\end{array}$ & Não priorizada & $\begin{array}{c}\text { Programa } \\
\text { Segundo Tempo } \\
\text { (PA) }\end{array}$ & $\begin{array}{c}\text { Relação professor-aluno e } \\
\text { entendimento da realidade } \\
\text { beneficiados pelo jornal } \\
\text { "Fanzine". }\end{array}$ \\
\hline
\end{tabular}


Continuação do quadro $1 .$.

\begin{tabular}{|c|c|c|c|c|c|}
\hline $\begin{array}{l}\text { Autores } \\
\text { (Ano) }\end{array}$ & Título & $\begin{array}{l}\text { Objetivo do } \\
\text { Estudo }\end{array}$ & $\begin{array}{l}\text { Pesquisa (tipo) / } \\
\text { Análise (tipo) / } \\
\text { Abordagem } \\
\text { Teórica }\end{array}$ & $\begin{array}{l}\text { Amostra / } \\
\text { Projeto ou } \\
\text { Programa }\end{array}$ & Principais resultados \\
\hline \multirow{3}{*}{$\begin{array}{l}\text { Souza et al. } \\
\qquad(2010)\end{array}$} & \multirow{3}{*}{$\begin{array}{l}\text { Determinantes para a } \\
\text { implementação de um } \\
\text { Projeto Social. }\end{array}$} & \multirow{3}{*}{$\begin{array}{l}\text { Investigar } \\
\text { facilitadores e } \\
\text { barreiras na } \\
\text { implementação e } \\
\text { participação dos } \\
\text { beneficiados. }\end{array}$} & Descritiva & \multirow{2}{*}{$\begin{array}{c}64 \text { integrantes } \\
\text { (coordenadores; } \\
\text { professores; } \\
\text { monitore; alunos) } \\
\end{array}$} & \multirow{3}{*}{$\begin{array}{l}\text { Principais facilitadores: gestão } \\
\text { municipal; empenho de } \\
\text { RH, gratuidade, segurança, } \\
\text { socialização. Principais } \\
\text { Barreiras: remuneração e } \\
\text { rotatividade de RH. }\end{array}$} \\
\hline & & & Qualitativa & & \\
\hline & & & Não priorizada & $\begin{array}{l}\text { Comunidade } \\
\text { Escola (PR) }\end{array}$ & \\
\hline \multirow{3}{*}{$\begin{array}{l}\text { Tavares, } \\
\text { Costa e } \\
\text { Tubino }\end{array}$} & \multirow{3}{*}{$\begin{array}{l}\text { Recreação Esportiva e } \\
\text { seus desafios corporais } \\
\text { no Complexo do } \\
\text { Alemão. }\end{array}$} & \multirow{3}{*}{$\begin{array}{l}\text { Analisar o esporte } \\
\text { como ferramenta } \\
\text { pẹdagógica de } \\
\text { bem-estar e } \\
\text { socialização. }\end{array}$} & Descritiva & \multirow{2}{*}{$\begin{array}{c}\text { Não } \\
\text { especificada }\end{array}$} & \multirow{3}{*}{$\begin{array}{l}\text { Proposta de formação } \\
\text { contempla "ser", "conhecer", } \\
\text { "fazer" e "conviver". O aluno } \\
\text { vivencia coparticipação } \\
\text { no processo de ensino- } \\
\text { aprendizagem. }\end{array}$} \\
\hline & & & Qualitativa & & \\
\hline & & & Não priorizada & $\begin{array}{l}\text { Cultura Corporal, } \\
\text { Esporte e Lazer } \\
\text { (RJ) }\end{array}$ & \\
\hline \multirow{3}{*}{$\begin{array}{l}\text { Castro e } \\
\text { Souza }\end{array}$} & \multirow{3}{*}{$\begin{array}{l}\text { Significados de um } \\
\text { projeto social esportivo: } \\
\text { um estudo a partir } \\
\text { das perspectivas de } \\
\text { profissionais, pais, } \\
\text { crianças e adolescentes. }\end{array}$} & \multirow{3}{*}{$\begin{array}{l}\text { Explorar os } \\
\text { principais } \\
\text { significados } \\
\text { atribuídos ao } \\
\text { projeto. }\end{array}$} & Descritiva & \multirow{2}{*}{$\begin{array}{l}85 \text { integrantes } \\
\text { (alunos; pais; } \\
\text { profissionais) }\end{array}$} & \multirow{3}{*}{$\begin{array}{l}\text { Projeto visto como espaço de } \\
\text { proteção, iniciação esportiva, } \\
\text { apoio escolar, desenvolvimento } \\
\text { de valores, diversão e } \\
\text { amizades. }\end{array}$} \\
\hline & & & Qualitativa & & \\
\hline & & & Não priorizada & $\begin{array}{l}\text { Esporte em } \\
\text { Ação (PR) }\end{array}$ & \\
\hline \multirow{3}{*}{$\begin{array}{l}\text { Machado } \\
\text { et al. }\end{array}$} & \multirow{3}{*}{$\begin{array}{l}\text { Pedagogia do esporte e } \\
\text { autonomia: um estudo } \\
\text { em projeto social de } \\
\text { educação não formal. }\end{array}$} & \multirow{3}{*}{$\begin{array}{l}\text { Identificar } \\
\text { estímulos ao } \\
\text { desenvolvimento } \\
\text { da autonomia } \\
\text { no planejamento } \\
\text { pedagógico. }\end{array}$} & Descritiva & \multirow{2}{*}{6 professores } & \multirow{3}{*}{$\begin{array}{l}\text { Os dados acusaram dificuldade } \\
\text { em sistematizar e aplicar } \\
\text { conteúdos na perspectiva } \\
\text { do desenvolvimento da } \\
\text { autonomia, um dos objetivos } \\
\text { do projeto. }\end{array}$} \\
\hline & & & Quali-quantitativa & & \\
\hline & & & Não priorizada & $\begin{array}{l}\text { Ensino, Esporte } \\
\text { e Juventude } \\
\text { (SP) }\end{array}$ & \\
\hline \multirow{3}{*}{$\begin{array}{l}\text { Mello et al. } \\
\text { (2011) }\end{array}$} & \multirow{3}{*}{$\begin{array}{c}\text { Educação Física e } \\
\text { esporte: reflexões e } \\
\text { ações contemporâneas. }\end{array}$} & \multirow{3}{*}{$\begin{array}{l}\text { Analisar a } \\
\text { apropriação } \\
\text { do esporte e } \\
\text { possibilidades de } \\
\text { relação com as } \\
\text { práticas. }\end{array}$} & Descritiva & \multirow{2}{*}{$\begin{array}{c}83 \text { alunos } \\
\text { (evadidos e } \\
\text { participantes) }\end{array}$} & \multirow{3}{*}{$\begin{array}{c}\text { Participantes rejeitaram a } \\
\text { proposta crítico-superadora. A } \\
\text { não vivência de experiências } \\
\text { esperadas provocou } \\
\text { desestímulo e/ou evasão. }\end{array}$} \\
\hline & & & Qualitativa & & \\
\hline & & & $\begin{array}{l}\text { Da relação com o } \\
\text { Saber (CHARLOT) }\end{array}$ & $\begin{array}{l}\text { Esporte Cidadão } \\
\text { (ES) }\end{array}$ & \\
\hline \multirow{3}{*}{$\begin{array}{l}\text { Mello, Votre } \\
\text { e Lovisolo }\end{array}$} & \multirow{3}{*}{$\begin{array}{c}\text { Evasão e permanência } \\
\text { no Projeto Esporte } \\
\text { Cidadão. }\end{array}$} & \multirow{3}{*}{$\begin{array}{l}\text { Descrever e } \\
\text { interpretar a } \\
\text { avaliação do } \\
\text { projeto por alunos } \\
\text { evadidos e } \\
\text { perseverantes. }\end{array}$} & Descritiva & \multirow{2}{*}{$\begin{array}{c}83 \text { alunos } \\
\text { (evadidos e } \\
\text { participantes) }\end{array}$} & \multirow{3}{*}{$\begin{array}{c}\text { Falhas detectadas: não } \\
\text { aquisição de habilidades } \\
\text { esportivas e negligência a } \\
\text { competições. Bons resultados } \\
\text { com mudança de prioridade } \\
\text { pedagógica. }\end{array}$} \\
\hline & & & Qualitativa & & \\
\hline & & & Não priorizada & $\begin{array}{l}\text { Esporte Cidadão } \\
\text { (ES) }\end{array}$ & \\
\hline \multirow{3}{*}{ Souza et al. } & \multirow{3}{*}{$\begin{array}{l}\text { Projeto de educação } \\
\text { pelo esporte: estudo } \\
\text { de caso sobre a } \\
\text { contribuição do Brinca } \\
\text { Mané na formação } \\
\text { discente. }\end{array}$} & & Descritiva & 16 monitore & Contribuição na construção \\
\hline & & contribuição & Qualitativa & & identitária do educador; \\
\hline & & $\begin{array}{l}\text { do projeto na } \\
\text { formação de } \\
\text { graduandos em } \\
\text { Educação Física. }\end{array}$ & Não priorizada & $\begin{array}{c}\text { Brinca Mané } \\
\text { (SC) }\end{array}$ & $\begin{array}{l}\text { ressignificação da vivência } \\
\text { curricular; reflexão crítica } \\
\text { sobre relações teoria-prática e } \\
\text { esporte-educação. }\end{array}$ \\
\hline & & & Descritiva & 25 professores & Professores não percebem \\
\hline $\begin{array}{l}\text { Vianna e } \\
\text { Lovisolo }\end{array}$ & & $\begin{array}{l}\text { Investigar a } \\
\text { percepcão de }\end{array}$ & Quali-quantitativa & & $\begin{array}{l}\text { nos alunos potenciais } \\
\text { esportivos; desacreditam }\end{array}$ \\
\hline (2011) & $\begin{array}{l}\text { A inclusão social através } \\
\text { do esporte: a percepção } \\
\text { dos educadores. }\end{array}$ & $\begin{array}{l}\text { professores sobre } \\
\text { seus alunos, e } \\
\text { a intervenção } \\
\text { institucional. }\end{array}$ & Não priorizada & $\begin{array}{l}\text { Projetos não } \\
\text { identificados- } \\
\text { Maré e Cidade } \\
\text { de Deus (RJ) }\end{array}$ & $\begin{array}{l}\text { esportivos; desacrealtam } \\
\text { na formação através do } \\
\text { esporte; não percebem em si } \\
\text { competência e não aparentam } \\
\text { comprometimento com a } \\
\text { instrumentalização de alunos. }\end{array}$ \\
\hline & "Uma andorinha só não & & Descritiva & & \\
\hline Alves, & faz verão": a integração & & Qualitativa & 33 protessores & Necessidades apresentadas: \\
\hline $\begin{array}{c}\text { Chaves e } \\
\text { Gontijo }\end{array}$ & $\begin{array}{l}\text { do educador físico na } \\
\text { rede de suporte social de } \\
\text { crianças e adolescentes } \\
\text { em situação de } \\
\text { vulnerabilidade: } \\
\text { discussões a partir de } \\
\text { um curso de educação } \\
\text { continuada. }\end{array}$ & $\begin{array}{c}\text { Descrever e } \\
\text { analisar conteúdos } \\
\text { da capacitação. }\end{array}$ & Não priorizada & Não identificado & $\begin{array}{l}\text { interfaces com outras áreas } \\
\text { na formação em Educação } \\
\text { Física; compreensão do papel } \\
\text { desse profissional na rede } \\
\text { de proteção dos direitos da } \\
\text { criança e do adolescente. }\end{array}$ \\
\hline
\end{tabular}


Continuação do quadro 1.

\begin{tabular}{|c|c|c|c|c|c|}
\hline $\begin{array}{l}\text { Autores } \\
\text { (Ano) }\end{array}$ & Título & $\begin{array}{l}\text { Objetivo do } \\
\text { Estudo }\end{array}$ & $\begin{array}{l}\text { Pesquisa (tipo) / } \\
\text { Análise (tipo) / } \\
\text { Abordagem } \\
\text { Teórica }\end{array}$ & $\begin{array}{l}\text { Amostra / } \\
\text { Projeto ou } \\
\text { Programa }\end{array}$ & Principais resultados \\
\hline \multirow[b]{3}{*}{$\begin{array}{l}\text { Araújo et al. } \\
\text { (2012) }\end{array}$} & \multirow{3}{*}{$\begin{array}{l}\text { Formação e atuação } \\
\text { pedagógica no } \\
\text { Programa Segundo } \\
\text { Tempo: reflexões sobre } \\
\text { o fazer cotidiano do } \\
\text { professor. }\end{array}$} & \multirow{3}{*}{$\begin{array}{c}\text { Refletir sobre } \\
\text { a prática } \\
\text { pedagógica, com } \\
\text { base nas diretrizes } \\
\text { do programa. }\end{array}$} & Descritiva & \multirow{2}{*}{66 professores } & \multirow{3}{*}{$\begin{array}{l}\text { Compreensão, mas } \\
\text { dificuldade de apropriação das } \\
\text { proposições. Capacitações } \\
\text { regionais, socialização de } \\
\text { experiências e formação } \\
\text { continuada são fundamentais } \\
\text { para o aprimoramento. }\end{array}$} \\
\hline & & & Quali-quantitativa & & \\
\hline & & & Não priorizada & $\begin{array}{c}\text { Programa } \\
\text { Segundo Tempo } \\
\text { (SE/AL) }\end{array}$ & \\
\hline \multirow{3}{*}{$\begin{array}{l}\text { Colombo } \\
\text { et al. }\end{array}$} & \multirow{3}{*}{$\begin{array}{l}\text { O Programa Segundo } \\
\text { Tempo: uma } \\
\text { política pública para } \\
\text { emancipação humana. }\end{array}$} & \multirow{3}{*}{$\begin{array}{l}\text { Relatar } \\
\text { criticamente } \\
\text { propostas, } \\
\text { experiências e } \\
\text { planejamento. }\end{array}$} & Descritiva & & \multirow{3}{*}{$\begin{array}{l}\text { Infraestrutura e criminalidade } \\
\text { interferem nas ações } \\
\text { pedagógicas. Gestão na } \\
\text { perspectiva emancipatória: } \\
\text { enfrentamento da evasão; } \\
\text { centralidade do conhecimento; } \\
\text { relação com as comunidades. }\end{array}$} \\
\hline & & & Qualitativa & especificado & \\
\hline & & & $\begin{array}{l}\text { Crítico-superadora } \\
\text { (SOARES et al.) }\end{array}$ & $\begin{array}{c}\text { Programa } \\
\text { Segundo Tempo } \\
\text { (SC) }\end{array}$ & \\
\hline \multirow{3}{*}{$\begin{array}{l}\text { Hirama e } \\
\text { Montagner }\end{array}$} & \multirow{3}{*}{$\begin{array}{l}\text { Algo para além de } \\
\text { tirar da rua: o ensino } \\
\text { do esporte em projeto } \\
\text { socioeducativo }\end{array}$} & \multirow{3}{*}{$\begin{array}{l}\text { Compreender } \\
\text { transformações } \\
\text { no cotidiano de } \\
\text { adolescentes } \\
\text { e contribuir na } \\
\text { estruturação do } \\
\text { eixo norteador }\end{array}$} & Descritiva & \multirow{2}{*}{$\begin{array}{l}32 \text { atores } \\
\text { (alunos; } \\
\text { professores; } \\
\quad \text { líder } \\
\text { comunitário) } \\
\end{array}$} & \multirow{3}{*}{$\begin{array}{c}\text { Destacaram-se: relação } \\
\text { professor-aluno; } \\
\text { pertencimento; continuidade no } \\
\text { aprendizado; aperfeiçoamento } \\
\text { pedagógico. }\end{array}$} \\
\hline & & & Qualitativa & & \\
\hline & & & Não priorizada & $\begin{array}{c}\text { Não } \\
\text { identificado }\end{array}$ & \\
\hline \multirow{3}{*}{$\begin{array}{l}\text { Kravchychyn } \\
\text { et al. }\end{array}$} & \multirow{3}{*}{$\begin{array}{l}\text { Avaliação do Programa } \\
\text { Segundo Tempo } \\
\text { no Estado de São } \\
\text { Paulo: realidades e } \\
\text { potencialidades. }\end{array}$} & \multirow{3}{*}{$\begin{array}{l}\text { Identificar } \\
\text { problemas, } \\
\text { qualidades e } \\
\text { possibilidades de } \\
\text { intervenção. }\end{array}$} & Descritiva & \multirow{2}{*}{58 professores } & \multirow{3}{*}{$\begin{array}{c}\text { Núcleos em escolas acusam } \\
\text { maior frequência e consistência } \\
\text { pedagógica. Contributos } \\
\text { da assessoria à gestão } \\
\text { dos projetos: coordenação } \\
\text { pedagógica, capacitação e } \\
\text { avaliação. }\end{array}$} \\
\hline & & & Quali-quantitativa & & \\
\hline & & & Não priorizada & $\begin{array}{c}\text { Programa } \\
\text { Segundo Tempo } \\
\text { (SP) }\end{array}$ & \\
\hline \multirow{3}{*}{$\begin{array}{l}\text { Souza, } \\
\text { Castro e } \\
\text { Mezzadri }\end{array}$} & \multirow{3}{*}{$\begin{array}{c}\text { Facilitadores e barreiras } \\
\text { para implementação e } \\
\text { participação em projetos } \\
\text { sociais que envolvem } \\
\text { atividades esportivas: } \\
\text { casos dos projetos Vila } \\
\text { na Escola e Esporte } \\
\text { Ativo. }\end{array}$} & \multirow[b]{3}{*}{$\begin{array}{l}\text { Levantar os } \\
\text { principais fatores } \\
\text { intervenientes na } \\
\text { implementação. }\end{array}$} & Descritiva & 78 atores & \multirow{3}{*}{$\begin{array}{c}\text { Facilitadores ou barreiras } \\
\text { (conforme o caso): qualificação } \\
\text { profissional; parcerias; } \\
\text { espaços; equipamentos; } \\
\text { atividades; envolvimento } \\
\text { comunitário. Facilitadores: } \\
\text { práticas esportivas; } \\
\text { socialização; segurança. } \\
\text { Principal barreira: insegurança } \\
\text { no entorno. }\end{array}$} \\
\hline & & & Qualitativa & $\begin{array}{l}\text { (alunos; pais; } \\
\text { profissionais) }\end{array}$ & \\
\hline & & & Não priorizada & $\begin{array}{l}\text { Vila na Escola } \\
\text { e Esporte Ativo } \\
\text { (PR) }\end{array}$ & \\
\hline \multirow{3}{*}{$\begin{array}{l}\text { Starepravo } \\
\text { et al. }\end{array}$} & \multirow{3}{*}{$\begin{array}{c}\text { As Equipes } \\
\text { Colaboradoras do } \\
\text { Programa Segundo } \\
\text { Tempo e suas } \\
\text { contribuições para o } \\
\text { desenvolvimento de } \\
\text { uma política de esporte } \\
\text { educacional. }\end{array}$} & \multirow{3}{*}{$\begin{array}{c}\text { Analisar o } \\
\text { funcionamento } \\
\text { das equipes e seu } \\
\text { acompanhamento } \\
\text { pedagógico e } \\
\text { administrativo. }\end{array}$} & Descritiva & \multirow{2}{*}{$\begin{array}{l}75 \text { integrantes } \\
\text { das equipes }\end{array}$} & \multirow{3}{*}{$\begin{array}{l}\text { O funcionamento das equipes } \\
\text { efetiva-se pela capacitação, } \\
\text { construção de projetos } \\
\text { pedagógicos, avaliações } \\
\text { in loco e assessoria, } \\
\text { ações fundamentais no } \\
\text { reconhecimento do programa } \\
\text { como política pública. }\end{array}$} \\
\hline & & & Quali-quantitativa & & \\
\hline & & & Não priorizada & $\begin{array}{l}\text { Programa } \\
\text { Segundo Tempo } \\
\text { (pesquisa } \\
\text { nacional) }\end{array}$ & \\
\hline \multirow{3}{*}{$\begin{array}{l}\text { Kalinoski } \\
\text { et al. }\end{array}$} & \multirow{3}{*}{$\begin{array}{l}\text { Núcleo especial do } \\
\text { Programa Segundo } \\
\text { Tempo na ESEF-UFPel. }\end{array}$} & \multirow{3}{*}{$\begin{array}{l}\text { Verificar os níveis } \\
\text { de atividade } \\
\text { física e inclusão } \\
\text { de pessoas com } \\
\text { deficiência. }\end{array}$} & Descritiva & \multirow{2}{*}{$\begin{array}{l}\text { Alunos e pais } \\
\quad \text { (N não } \\
\text { especificado) }\end{array}$} & \multirow{3}{*}{$\begin{array}{l}\text { Melhora da aptidão física, } \\
\text { desempenho motor, controle } \\
\text { de stress, ansiedades/ } \\
\text { frustrações, autoestima, } \\
\text { autoimagem, autonomia, } \\
\text { socialização, motivação e } \\
\text { diminuição do preconceito. }\end{array}$} \\
\hline & & & Qualitativa & & \\
\hline & & & Não priorizada & $\begin{array}{c}\text { Programa } \\
\text { Segundo Tempo } \\
\text { (RS) }\end{array}$ & \\
\hline \multirow[b]{3}{*}{$\begin{array}{l}\text { Souza et al. } \\
\qquad \text { (2013) }\end{array}$} & & & Descritiva & 8 atores & Considerou-se a \\
\hline & $\begin{array}{l}\text { Análise do educador } \\
\text { sobre implantação }\end{array}$ & $\begin{array}{l}\text { Compreender as } \\
\text { possibilidades }\end{array}$ & Quali-quantitativa & $\begin{array}{l}\text { (professores; } \\
\text { monitores }\end{array}$ & $\begin{array}{l}\text { utilização apropriada } \\
\text { pelos pesquissadores }\end{array}$ \\
\hline & $\begin{array}{l}\text { de cartões de apoio } \\
\text { pedagógico no } \\
\text { Programa Segundo } \\
\text { Tempo. }\end{array}$ & $\begin{array}{l}\text { de aplicação } \\
\text { dos cartões nas } \\
\text { atividades do } \\
\text { programa. }\end{array}$ & Não priorizada & $\begin{array}{c}\text { Programa } \\
\text { Segundo Tempo } \\
\text { (SC/AL) }\end{array}$ & $\begin{array}{c}(75,5 \%) \text { e educadores } \\
(72,7 \%) \text {. Necessidade de } \\
\text { aprimoramento da capacitação } \\
\text { dos educadores para domínio } \\
\text { dessa tecnologia. }\end{array}$ \\
\hline
\end{tabular}


Continuação do quadro $1 .$.

\begin{tabular}{|c|c|c|c|c|c|}
\hline $\begin{array}{c}\text { Autores } \\
\text { (Ano) }\end{array}$ & Título & $\begin{array}{c}\text { Objetivo do } \\
\text { Estudo }\end{array}$ & $\begin{array}{l}\text { Pesquisa (tipo) / } \\
\text { Análise (tipo) / } \\
\text { Abordagem } \\
\text { Teórica }\end{array}$ & $\begin{array}{l}\text { Amostra / } \\
\text { Projeto ou } \\
\text { Programa }\end{array}$ & Principais resultados \\
\hline \multirow{2}{*}{$\begin{array}{c}\text { Souza, } \\
\text { Souza e } \\
\text { Castro }\end{array}$} & \multirow{3}{*}{$\begin{array}{l}\text { Barreiras e facilitadores } \\
\text { para a implementação } \\
\text { do Programa } \\
\text { SegundoTempo: um } \\
\text { estudo de caso. }\end{array}$} & \multirow{3}{*}{$\begin{array}{c}\text { Identificar } \\
\text { facilitadores e } \\
\text { barreiras para a } \\
\text { implementação do } \\
\text { programa. }\end{array}$} & Descritiva & \multirow{2}{*}{$\begin{array}{c}8 \text { atores } \\
\text { (coordenador; } \\
\text { professores) }\end{array}$} & \multirow{3}{*}{$\begin{array}{l}\text { Facilitadores: materiais; } \\
\text { planejamento; reforço } \\
\text { alimentar. Barreiras ou } \\
\text { facilitadores (conforme o caso): } \\
\text { estrutura física; materiais; } \\
\text { programas próximos. }\end{array}$} \\
\hline & & & Qualitativa & & \\
\hline Castro & & & Não priorizada & $\begin{array}{l}\text { Programa } \\
\text { Segundo Tempo } \\
\text { (Município da } \\
\text { Região Sul) }\end{array}$ & \\
\hline
\end{tabular}

Fonte: dos autores.

Em termos quantitativos, verifica-se, durante a primeira metade do período, uma publicação por ano em 2004, 2005, 2006 e 2007 ( $n=4 ; 14 \%$ ), e uma interrupção nas publicações sobre o tema no ano de 2008. Os demais artigos $(n=24 ; 86 \%)$ foram publicados na segunda metade do período, a partir de 2009, acompanhando a crescente demanda na oferta dos PPSE no Brasil (MELO, 2008; STIGGER; THOMASSIM, 2013). Tal demanda provavelmente tenha influenciado a notória predominância de estudos de caso sobre o tema, previamente indicada por Souza et al. (2010).

No que tange a análises pautadas em um referencial teórico específico ou predominante, apenas oito (29\%) dos artigos selecionados apresentaram essa condição, enquanto vinte (71\%) apresentaram análises e discussões sob bases teóricas diversificadas, utilizadas pontualmente, de acordo com cada abordagem.

A seleção apresenta estudos municipais ( $n=24 ; 86 \%)$, regionais $(n=3 ; 10 \%)$ e de abrangência nacional $(n=1 ; 4 \%)$.

Foram utilizados instrumentos elaborados pelos próprios pesquisadores em todos os artigos: roteiros de entrevistas ( $n=18 ; 64 \%)$; critérios de análise documental $(n=8 ; 29 \%)$; fichas de observação e diários de campo ( $n=12 ; 43 \%)$; e questionários ( $n=6 ; 21 \%)$. Dois trabalhos (8\%) apresentaram complementarmente protocolos validados em outros estudos e $13(46 \%)$ utilizaram dois ou mais instrumentos.

Colaboraram diretamente nas pesquisas: professores ${ }^{4}$ e monitores $(n=13 ; 52 \%)$, alunos $(n=15 ; 60 \%)$, gestores/coordenadores $(n=4 ; 16 \%)$, pais/responsáveis $(n=4 ; 16 \%)$, voluntários e outros profissionais ( $n=3 ; 12 \%)$; membros da comunidade $(n=1 ; 4 \%)$; e avaliadores externos $(n=1 ; 4 \%)$. Duas ou mais categorias de sujeitos colaboraram em oito artigos (32\%).

Todos os estudos apresentaram análises qualitativas, sendo: 18 (64\%) integralmente; nove (32\%) trazendo dados quantitativos como apoio (quali-quantitativa); e uma (4\%) priorizando dados quantitativos (quanti-qualitativa).

A Tabela 1 apresenta a categorização dos estudos, pautada nas abordagens efetuadas em cada um deles, buscando favorecer as análises subsequentes. 
Tabela 1 - Categorização dos estudos

\begin{tabular}{lcc}
\hline Categorias & N & $\%$ \\
\hline Gestão & 12 & 43 \\
Conteúdos e métodos de ensino & 9 & 32 \\
Formação e intervenção profissional & 7 & 25 \\
\hline Total & $\mathbf{2 8}$ & 100 \\
\hline & Fonte: dos autores. &
\end{tabular}

A categoria "gestão" (MELO, 2005; DÓRIA; TUBINO, 2006; MACHADO et al., 2007; VIANNA; LOVISOLO, 2009a; MATTOS et al., 2010; SOUZA et al., 2010; MELLO et al., 2011; MELLO; VOTRE; LOVISOLO, 2011; COLOMBO et al., 2012; KRAVCHYCHYN et al., 2012; SOUZA; CASTRO; MEZZADRI, 2012; SOUZA; SOUZA; CASTRO, 2013) foi a mais contemplada individualmente $(n=12 ; 43 \%)$. Contudo, somando-se "conteúdos e métodos de ensino" (MOLINA; SILVA; SILVEIRA, 2004; VIANNA; LOVISOLO, 2009b; LAZZARI; THOMASSIM; STIGGER, 2010; TAVARES; COSTA; TUBINO, 2010; CASTRO; SOUZA, 2011; MACHADO et al., 2011; HIRAMA; MONTAGNER, 2012; KALINOSKI et al., 2013; SOUZA et al., 2013) e "formação e intervenção profissional" (SOUZA et al., 2011; ALVES; CHAVES; GONTIJO, 2012; ARAÚJO et al., 2012; STAREPRAVO et al., 2012; MELLO; FERREIRA NETO; VOTRE, 2009; MONTEIRO, 2010; VIANNA; LOVISOLO, 2011), verifica-se a predominância de abordagens pedagógicas $(n=16 ; 57 \%)$.

\subsection{Gestão}

Projetos e programas sociais geralmente apresentam complexos processos de estruturação, implementação e avaliação (COHEN; FRANCO, 2008). Os PPSE brasileiros priorizam beneficiados em situação de risco/vulnerabilidade social (CORREIA, 2008; MELO, 2008; LAZZARI; THOMASSIM; STIGGER, 2010; ALVES; CHAVES E GONTIJO, 2012). Dita 0 senso comum que a juventude deve ser "tirada das ruas" e levada até locais de prática esportiva orientada, livre dos males urbanos (ZALUAR, 1994), visão salvacionista (MELO, 2005; MELO, 2008; LAZZARI; THOMASSIM; STIGGER, 2010) comumente geradora de generosidade no estabelecimento de objetivos e, consequentemente, de dificuldades de gestão (CORREIA, 2008).

A implementação tematizou três artigos selecionados (SOUZA et al., 2010; SOUZA; CASTRO; MEZZADRI, 2012; SOUZA; SOUZA; CASTRO, 2013), que apresentam dados consensuais com outras realidades estudadas: dificuldades, como rotatividade de recursos humanos (KRAVCHYCHYN et al., 2012) e insegurança no entorno das sedes (VIANNA; LOVISOLO, 2009a; COLOMBO et al., 2012), bem como constatações positivas, como a da relevância da participação das comunidades nos processos decisórios (DÓRIA; TUBINO, 2006; MELLO; FERREIRA NETO; VOTRE, 2009; MATTOS et al., 2010; VIANNA; LOVISOLO, 2011; MELLO; VOTRE; LOVISOLO, 2011; ALVES; CHAVES; GONTIJO, 2012; COLOMBO et al., 2012; HIRAMA; MONTAGNER, 2012; KRAVCHYCHYN et al., 2012) e de parcerias com instituições de ensino superior (IES) (MOLINA; SILVA; SILVEIRA, 2004; MACHADO et al., 2007; MELLO; FERREIRA NETO; VOTRE, 2009; LAZZARI; THOMASSIM; STIGGER, 2010; SOUZA et al., 2011; COLOMBO et al., 2012; ARAÚJO et al., 2012; KRAVCHYCHYN et al., 2012; STAREPRAVO et al., 2012; KALINOSKI et al., 2013). 
Em geral, parcerias projeto-escola mostraram-se eficazes (MACHADO et al., 2007; MELLO; FERREIRA NETO; VOTRE, 2009; SOUZA et al., 2010; TAVARES; COSTA; TUBINO, 2010; MELLO et al., 2011; MELLO; VOTRE; LOVISOLO, 2011; SOUZA; CASTRO; MEZZADRI, 2012; COLOMBO et al., 2012). Contudo, há relatos pontuais de restrições no atendimento de alunos não matriculados em escolas-sede (SOUZA; SOUZA; CASTRO, 2013), disputas por espaços esportivos com atividades escolares (KRAVCHYCHYN et al., 2012) e substituição do componente curricular Educação Física por atividades do projeto, equívoco institucional e pedagógico que enfraquece ambas as estruturas (MELO, 2005).

Poucos estudos registraram parcerias com a iniciativa privada (MELO, 2005; SOUZA et al., 2010; HIRAMA; MONTAGNER, 2012; SOUZA; CASTRO; MEZZADRI, 2012), contraditando o suposto interesse do setor em incentivos fiscais e imagem de responsabilidade social (MELO, 2008).

Quanto às ações de avaliação, verificam-se experiências positivas de socialização, partindo de observações das atividades e/ou depoimentos de seus atores (MOLINA; SILVA; SILVEIRA, 2004; DÓRIA; TUBINO, 2006; MACHADO et al., 2007; MELLO; FERREIRA NETO; VOTRE, 2009; LAZZARI; THOMASSIM; STIGGER, 2010; MACHADO et al., 2011; VIANNA; LOVISOLO, 2011; KALINOSKI et al., 2013). Entretanto, a baixa aderência às atividades, verificada em um dos estudos (VIANNA; LOVISOLO, 2009a), pareceu gerar insuficiência de tempo para um processo socializador.

Em parte dos projetos pesquisados, fatores como evasão e/ou baixa frequência são relacionados à desorganização pedagógica (MELO, 2005; VIANNA; LOVISOLO, 2009a; MELLO et al., 2011; MELLO; VOTRE; LOVISOLO, 2011; COLOMBO et al., 2012; KRAVCHYCHYN et al., 2012). Em contraponto, o planejamento pedagógico participativo (VIANNA; LOVISOLO, 2009a; MATTOS et al., 2010; TAVARES; COSTA; TUBINO, 2010; COLOMBO et al., 2012; MELLO; VOTRE; LOVISOLO, 2011; KRAVCHYCHYN et al., 2012; KALINOSKI et al., 2013) e a instrumentalização para aplicação dos saberes na sociedade (DÓRIA; TUBINO, 2006; MACHADO et al., 2011) mostraram-se ações eficazes para aderência e retenção.

Em PPSE, percebe-se a predominância de avaliações de processo sobre as de impacto. Os dois modelos diferenciam-se significativamente, conforme orientam Cohen e Franco (2008, p. 118):

\begin{abstract}
A avaliação de processo preocupa-se mais em melhorar a eficiência operativa do que em determinar os impactos do projeto. Para isso, elabora um diagnóstico sobre o estado do projeto, procurando detectar fatores que limitam a possibilidade de alcançar seus objetivos; apresenta soluções que tendem a superar essas restrições; e as tornam válidas em um subconjunto do processo. A determinação de impacto, porém, exige aplicar modelos experimentais ou quase-experimentais, considerando momentos (antes e depois), requerendo também controlar os efeitos não atribuíveis ao projeto.
\end{abstract}

Sob tais critérios, embora avaliações de impacto constem em três propósitos de pesquisa (MOLINA; SILVA; SILVEIRA, 2004; MATTOS et al., 2010; VIANNA; LOVISOLO, 2011), estes não apresentaram efetividade. Já dois estudos efetivaram avaliações de impacto, verificando a interferência das atividades no desempenho escolar e níveis de stress infantil e qualidade de vida dos alunos (MACHADO et al., 2007) e divulgando resultados de avaliações de crescimento e comportamento de alunos com deficit intelectual (KALINOSKI et al., 2013). 
Evidencia-se, pois, estreita relação entre questões administrativas e pedagógicas no âmbito dos PPSE. Aspectos pedagógicos são tratados especificamente nas categorias subsequentes.

\subsection{Conteúdos e métodos de ensino}

A abordagem da prática pedagógica nos PPSE basear-se-á nos referenciais "socioeducativo" e "técnico-tático" sugeridos por Galatti et al. (2008), considerando fatores como vulnerabilidade/risco social, inclusão, cidadania e promoção da saúde (socioeducativo) e ensino-aprendizagem do esporte educacional (socioeducativo e técnico-tático). O referencial socioeducativo (MOLINA; SILVA; SILVEIRA, 2004; VIANNA; LOVISOLO, 2009b; LAZZARI; THOMASSIM; STIGGER, 2010; TAVARES; COSTA; TUBINO, 2010; CASTRO; SOUZA, 2011; MACHADO et al., 2011; HIRAMA; MONTAGNER, 2012; KALINOSKI et al., 2013) apresenta absoluta predominância em relação ao técnico-tático (SOUZA et al., 2013) nas publicações.

No referencial socioeducativo, observam-se preocupações com ensino, desenvolvimento e promoção da saúde (MOLINA; SILVA; SILVEIRA, 2004; MACHADO et al., 2007; VIANNA; LOVISOLO, 2009a; 2011; SOUZA et al., 2010; TAVARES; COSTA; TUBINO, 2010; ALVES; CHAVES; GONTIJO, 2012; SOUZA; CASTRO; MEZZADRI, 2012; STAREPRAVO et al., 2012; KALINOSKI et al., 2013), autonomia (DÓRIA; TUBINO, 2006; MACHADO et al., 2007; MELLO; FERREIRA NETO; VOTRE, 2009; TAVARES; COSTA; TUBINO, 2010; MACHADO et al., 2011; SOUZA et al., 2012), cooperação (DÓRIA; TUBINO, 2006; MACHADO et al., 2007; MELLO; FERREIRA NETO; VOTRE, 2009; TAVARES; COSTA; TUBINO, 2010; MACHADO et al., 2011; SOUZA et al., 2012), socialização (MOLINA; SILVA; SILVEIRA, 2004; MACHADO et al., 2007; MELLO; FERREIRA NETO; VOTRE, 2009; TAVARES; COSTA; TUBINO, 2010; LAZZARI; THOMASSIM; STIGGER, 2010; SOUZA; CASTRO; MEZZADRI, 2012) e cidadania (DÓRIA; TUBINO, 2006; MELLO; FERREIRA NETO; VOTRE, 2009; VIANNA; LOVISOLO, 2009a; LAZZARI; THOMASSIM; STIGGER, 2010; SOUZA et al., 2010; TAVARES; COSTA; TUBINO, 2010; MACHADO et al., 2011; ALVES; CHAVES; GONTIJO, 2012; ARAÚJO et al.; 2012; KRAVCHYCHYN et al., 2012; SOUZA; CASTRO; MEZZADRI, 2012; STAREPRAVO et al., 2012), bem como com a inibição do consumo de drogas (MOLINA; SILVA; SILVEIRA, 2004; MONTEIRO, 2010; TAVARES; COSTA; TUBINO, 2010; CASTRO; SOUZA, 2011; COLOMBO et al., 2012; SOUZA; CASTRO; MEZZADRI, 2012), destacando-se a oferta de conteúdos voltados ao bemestar individual e coletivo e às questões éticas, transversalidade recorrente nesses estudos.

Já no técnico-tático, prioriza-se a necessidade de resgatar a instrumentalização dos alunos para a prática (VIANNA; LOVISOLO, 2009a; 2011; CASTRO; SOUZA, 2011; MACHADO et al., 2011; MELLO et al., 2011; MELLO; VOTRE; LOVISOLO, 2011; ARAÚJO et al., 2012; HIRAMA; MONTAGNER, 2012; KRAVCHYCHYN et al., 2012; SOUZA; CASTRO; MEZZADRI, 2012; KALINOSKI et al., 2013) e a participação em competições e festivais, procurando desmistificar a suposta nocividade dessas ações à formação dos alunos (MOLINA; SILVA; SILVEIRA, 2004; MELLO; FERREIRA NETO; VOTRE, 2009; VIANNA; LOVISOLO, 2009b; 2011; SOUZA et al., 2010; TAVARES; COSTA; TUBINO, 2010; MACHADO et al., 2011; MELLO et al., 2011; MELLO; VOTRE; LOVISOLO, 2011; HIRAMA; MONTAGNER, 2012), principalmente considerando seus anseios e justificativas para adesão e permanência (MOLINA; SILVA; SILVEIRA, 2004; MELLO; FERREIRA NETO; VOTRE, 2009; SOUZA et al., 
2010; MELLO et al., 2011; MELLO; VOTRE; LOVISOLO, 2011; VIANNA; LOVISOLO, 2011; SOUZA; CASTRO; MEZZADRI, 2012). O único estudo sobre "como ensinar" (SOUZA et al., 2013) avaliou uma metodologia referenciada na utilização do jogo como forma incidental de aprendizado esportivo.

Os relatos expuseram boas práticas, dificuldades e resistências na atuação profissional em PPSE, mas também dificuldades na apresentação de propostas concretas de intervenção, fatores que fomentam a discussão sobre a formação específica.

\subsection{Formação e intervenção profissional}

A demanda e as especificidades dos PPSE requerem maior atenção dos cursos de formação inicial em Educação Física (ALVES; CHAVES; GONTIJO, 2012; ARAÚJO et al., 2012). Capacitação de professores e formação continuada são ações que ganham, pois, relevância nesse contexto (SOUZA et al., 2011; ARAÚJO et al., 2012; STAREPRAVO et al., 2012).

Provavelmente devido à utilização comum de preceitos do esporte educacional, como inclusão, participação, cooperação, coeducação e corresponsabilidade (TUBINO, 2010), observa-se forte relação entre propostas pedagógicas de PPSE e bases teóricas da Educação Física Escolar (VIANNA; LOVISOLO, 2009a; 2009b; 2011; MELLO; VOTRE; FERREIRA NETO, 2009; TAVARES; COSTA; TUBINO, 2010; MACHADO et al., 2011; ARAÚJO et al., 2012).

Ao mesmo tempo em que a elaboração de projetos pedagógicos pressupõe um referencial teórico, peculiaridades dos PPSE sugerem cuidados na construção de sua práxis pedagógica.

O distanciamento resultante ora da supervalorização do conhecimento teórico, ora do pragmatismo da prática reinante no processo de formação deve ser quebrado pelo processo de aproximação, de mudança de olhar, na tentativa de minimizar o distanciamento entre o saber produzido pela academia e o desenvolvido no projeto (SOUZA et al., 2011, p. 8).

Constitui exemplo dessa aproximação o processo de capacitação e formação continuada do Programa Segundo Tempo (PST), do governo federal, descrito em alguns dos trabalhos publicados (ARAÚJO et al., 2012; STAREPRAVO et al., 2012; KRAVCHYCHYN et al., 2012; KALINOSKI et al., 2013).

Comumente objetivada nos PPSE, a formação integral dos beneficiados perspectiva a aproximação às suas realidades, necessidades e anseios - ressaltada nesta categoria ${ }^{5}$ e sugere 0 aprimoramento da relação professor-aluno (LAZZARI; THOMASSIM; STIGGER, 2010) e a necessidade de formação profissional para atuação como agente social nesse ambiente (MONTEIRO, 2010; ALVES; CHAVES; GONTIJO, 2012).

São relatadas situações de aproximação e distanciamento na relação professor-aluno, passíveis de reflexões para ações de formação. Verificam-se distanciamentos mediante relações excessivamente hierarquizadas (MELLO; FERREIRA NETO; VOTRE, 2009) e desconsideração de dificuldades dos alunos pelos professores (VIANNA; LOVISOLO, 2011). E aproximação, pela confecção conjunta de um jornal, decisiva na compreensão da realidade social local e relação entre as partes (MONTEIRO, 2010).

5 A "voz" de alunos de PPSE embasou análises de autores de $50 \%$ do total de artigos selecionados, demonstrando a importância dada a esses atores pelos pesquisadores. 


\section{CONCLUSÃO}

A categoria "gestão" contemplou principalmente os itens implementação, desenvolvimento, avaliação e continuidade, expondo principalmente: a) a preocupação com a supervalorização da prática esportiva orientada como promotora de aptidões, valores e atitudes positivas; b) a recomendação para ao envolvimento efetivo das comunidades nos processos decisórios; c) a valorização de parcerias; d) a preocupação com a evasão, indicando-se a organização pedagógica como principal solução; e) o predomínio de avaliações de processo sobre as de impacto.

Na categoria "conteúdos e métodos de ensino", o referencial socioeducativo predomina sobre o técnico-tático, indicando prioritariamente que: a) o referencial socioeducativo preconiza a otimização das perspectivas de vida dos alunos, por meio de aprendizados e vivências esportivas; b) o referencial técnico-tático apresenta um movimento pelo resgate de sua valorização, amparado pelas expectativas dos alunos; c) o interesse pelo referencial técnicotático contrasta com a escassez de pesquisas sobre metodologia do ensino do esporte nos PPSE.

Já os dados da categoria "formação e intervenção profissional" revelam principalmente: a) a priorização do processo de capacitação profissional e formação continuada, considerando a abordagem insuficiente da prática pedagógica nos PPSE nos cursos de formação inicial em Educação Física; b) a necessidade de atuação do professor como agente social, aproximando-o das comunidades atendidas.

A diversidade focal e a amplitude geográfica apresentada pelos pesquisadores que foram a campo denotam a validade pragmática (DE-LA-TORRE-UGARTE-GUANILO; TAKAHASHI; BERTOLOZZI, 2011) deste estudo, contemplando a problematização inicial, que prevê a apresentação de possibilidades de intervenção profissional em PPSE.

Em contraponto, com vistas aos direcionamentos de pesquisa, verifica-se que a produção ora tratada reforça as indicações da hegemonia absoluta de estudos de caso sobre PPSE (SOUZA et al., 2010) e da escassez de abordagens teóricas norteadoras em pesquisas sobre políticas públicas de esporte e lazer no Brasil (STAREPRAVO; SOUZA; MARCHI JÚNIOR, 2013), campo que abrange os PPSE. O vínculo prioritário a bases teóricas sociológicas, filosóficas, educacionais e político-ideológicas é apresentado em apenas uma terça parte dos estudos selecionados, carência que indica uma especial atenção na composição de futuros projetos de pesquisa sobre o tema.

Em geral, apresenta-se um panorama de pesquisa marcadamente empírico, sob o qual o problema nasce de uma situação ditada pela realidade observada, não emergindo no seio de uma problemática teórica (PRAIA; CACHAPUZ; GIL-PÉREZ, 2002). A maioria dos estudos apresenta direcionamentos educacionais e pedagógicos, com destaque para a utilização de referenciais teórico-metodológicos da Educação Física Escolar, que inicialmente orientaram 0 processo de ensino-aprendizagem do esporte educacional em PPSE. Especialmente a partir de 2009, com o progressivo interesse científico-acadêmico pelo tema, verifica-se um aumento de propostas pedagógicas direcionadas especificamente a essa manifestação esportiva relativamente recente, fator observável nos artigos que compõem as categorias "conteúdos e métodos de ensino" e "formação e intervenção profissional". 
Considerando a argumentação exposta e o potencial subsídio a pesquisas futuras, este estudo expõe como principais lacunas investigativas: a) avaliações de impacto de PPSE junto a beneficiados e comunidades envolvidas; b) como ensinar e desenvolver o esporte educacional em PPSE; c) tratamento da formação profissional em Educação Física (inicial e continuada) para atuação nesse contexto.

\section{REFERÊNCIAS}

ALVES, Heliana Castro; CHAVES, Aline Dessupoio; GONTIJO, Daniela Tavares. Uma andorinha só não faz verão: a integração do educador físico na rede de suporte social de crianças e adolescentes em situação de vulnerabilidade: discussões a partir de um curso de educação continuada. Pensar a Prática, Goiânia, v.15, n.2, p.331-347, abr./jun.2012.

ARAÚJJO, Allyson Carvalho et al. Formação e atuação pedagógica no Programa Segundo Tempo: reflexões sobre o fazer cotidiano do professor. Motrivivência, Florianópolis, v. 24, n.38, p.40-58, jun.2012.

CASTRO, Sueli Barbosa Eiras; SOUZA, Doralice Lange. Significados de um projeto social esportivo: um estudo a partir das perspectivas de profissionais, pais, crianças e adolescentes. Movimento, Porto Alegre, v.17, n. 4, p.145-163, out./dez.2011.

COHEN, Ernesto; FRANCO, Rolando. Avaliação de projetos sociais. Petrópolis: Vozes, 2008.

COLOMBO, Bruno Dandolini et al. O Programa Segundo Tempo: uma política pública para emancipação humana. Motrivivência, Florianópolis, v. 24, n.38, p.12-23, jun.2012.

CORREIA, Marcos Miranda. Projetos sociais em educação física, esporte e lazer: reflexões preliminares para uma gestão social. Revista Brasileira de Ciências do Esporte, Campinas, v.29, n.3, p.91-105, maio 2008.

DE-LA-TORRE-UGARTE-GUANILO, Maria Cecília; TAKAHASHI, Renata Ferreira; BERTOLOZZI, Maria Rita. Revisão sistemática: noções gerais. Revista da Escola de Enfermagem USP, São Paulo, v.45, n.5, p.1260-1266, out. 2011.

DÓRIA, Carlos; TUBINO, Manoel José Gomes. Avaliação da busca da cidadania pelo Projeto Olímpico da Mangueira. Ensaio: Avaliação e Políticas Públicas em Educação, Rio de Janeiro, v.14, n.50, p.77-90, jan./mar.2006.

GALATTI, Larissa Rafaela et al. Pedagogia do esporte: procedimentos pedagógicos aplicados aos jogos esportivos coletivos. Conexões, Campinas, v.6, p.397-408, jul.2008. Edição especial.

GOMES, Isabelle Sena; CAMINHA, Iraquitan Oliveira. Guia para estudos de revisão sistemática: uma opção metodológica para as ciências do movimento humano. Movimento, Porto Alegre, v.20, n.1, p.395-411, jan./mar.2014.

HIRAMA, Leopoldo Katsuki; MONTAGNER, Paulo César. Algo para além de tirar da rua: o ensino do esporte em projeto socioeducativo. Revista Brasileira de Ciências do Esporte, Florianópolis, v.34, n.1, p.149-164, jan./mar.2012.

KALINOSKI, Angélica Xavier et al. Núcleo Especial do Programa Segundo Tempo na Esef-Ufpel. Revista Brasileira de Atividade Física e Saúde, Pelotas, v.18, n.2, p.236-241, mar. 2013. 
KRAVCHYCHYN, Claudio et al. Avaliação do Programa Segundo Tempo no Estado de São Paulo: realidades e potencialidades. Coleção Pesquisa em Educação Física, Jundiaí, v.11, n.5, p.31-38, 2012.

LAZZARI, André; THOMASSIM, Luís Eduardo Cunha; STIGGER, Marco Paulo. A socialização de crianças e adolescentes no contexto de um projeto social de tênis. Caderno de Educação Física, Marechal Cândido Rondon, v.9, n.16, p.51-64, 1.sem.2010.

MACHADO, Gisele Viola et al. Pedagogia do esporte e autonomia: um estudo em projeto social de educação não formal. Pensar a Prática, Goiânia, v.14, n.3, p.1-21, set./dez.2011.

MACHADO, Paula Xavier et al. O impacto de um projeto de educação pelo esporte no desenvolvimento infantil. Psicologia Escolar e Educacional, Maringá, v.11, n.1, p.51-62, jan./ jun.2007.

MATTOS, Daniel Corrêa et al. O esporte náutico e a dinâmica da hélice tríplice no projeto Grael: um estudo de caso. Movimento, Porto Alegre, v.16, n.3, p.221-239, jul./set.2010.

MELLO, André Silva et al. Educação física e esporte: reflexões e ações contemporâneas. Movimento, Porto Alegre, v.17, n.2, p.175-193, abr./jun.2011.

MELLO, André Silva; FERREIRA NETO, Amarílio; VOTRE, Sebastião Josué. Intervenção da educação física em projetos sociais: uma experiência de cidadania e esporte em Vila Velha (ES). Revista Brasileira de Ciências do Esporte, Campinas, v.31, n.1, p.75-91, set.2009.

MELLO, André Silva; VOTRE, Sebastião Josué; LOVISOLO, Hugo Rodolfo. Evasão e permanência no projeto esporte cidadão. Licere, Belo Horizonte, v.14, n.1, p.1-18, mar. 2011.

MELO, Marcelo Paula. A Vila Olímpica da Maré e as políticas públicas de esporte no Rio de Janeiro: um debate sobre a relação lazer, esporte e escola. Movimento, Porto Alegre, v.11, n.3, p.89-106, set./dez.2005.

MELO, Victor Andrade. Projetos sociais de esporte e lazer: reflexões, inquietações, sugestões. Quaderns d'Animació i Educació Social, Sagunto, n.7, p.1-24, jan.2008.

MOLINA, Rosane Maria Kreusburg; SILVA, Lisandra Oliveira; SILVEIRA, Fabiano Vaz. Celebração e transgressão: a representação do esporte na adolescência. Revista Brasileira de Educação Física e Esporte, São Paulo, v.18, n.2, p.125-36, abr.jun.2004.

MONTEIRO, Victor Hugo Lima. Projeto Segundo Tempo: o Fanzine e a leitura do esporte em bairros violentos. Conexões, Campinas, v.8, n.3, p.10-15, set./dez.2010.

PRAIA, João Félix; CACHAPUZ, António Francisco Carrelhas; GIL-PÉREZ, Daniel. Problema, teoria e observação em ciência: para uma reorientação epistemológica da educação em ciência. Ciência \& Educação, Bauru,v.8, n.1, p.127-145, 2002.

ROMANOWSKI, Joana Paulin; ENS, Romilda Teodora. As pesquisas denominadas do tipo "estado da arte" em educação. Diálogo Educacional, Curitiba, v.6, n.19, p.37-50, set./dez. 2006.

SOUZA, Ana Paula Prestes; SOUZA, Doralice Lange; CASTRO, Suélen Barboza Eiras. Barreiras e facilitadores para a implementação do Programa Segundo Tempo: um estudo de caso. Pensar a Prática, Goiânia, v.16, n.4, p.997-1013, out./dez.2013.

SOUZA, Doralice Lange; CASTRO, Suélen Barbosa Eiras; MEZZADRI, Fernando Marinho. Facilitadores e barreiras para a implementação e participação em projetos sociais que envolvem 
atividades esportivas: os casos dos projetos Vila na Escola e Esporte Ativo. Revista Brasileira de Educação Física e Esporte, São Paulo, v.26, n.3, p.419-30, jul./set.2012.

SOUZA, Doralice Lange et al. Determinantes para a implementação de um projeto social. Motriz, Rio Claro, v.16, n.3, p.689-700, jul./set.2010.

SOUZA, Edison Roberto et al. Análise do educador sobre implantação de cartões de apoio pedagógico no Programa Segundo Tempo. Revista Mackenzie de Educação Física e Esporte, v.12, n.1, p.41-52, 2013.

SOUZA, Edison Roberto et al. Projeto de educação pelo esporte: estudo de caso sobre a contribuição do Brinca Mané na formação discente. Pensar a Prática, Goiânia, v.14, n.1, p.1-12, jan./abr.2011.

STAREPRAVO, Fernando Augusto et al. As Equipes Colaboradoras do Programa Segundo Tempo e suas contribuições para o desenvolvimento de uma política de esporte educacional. Motrivivência, Florianópolis, v. 24, n.38, p.129-141, jun.2012.

STAREPRAVO, Fernando Augusto; SOUZA, Juliano; MARCHI JÚNIOR, Wanderley. Políticas públicas de esporte e lazer no Brasil: uma argumentação inicial sobre a importância da utilização da teoria dos campos de Pierre Bourdieu. Revista Brasileira de Ciências do Esporte, Florianópolis, v. 35, n. 3, p. 785-798, jul./set.2013.

STIGGER, Marco Paulo; THOMASSIM, Luís Eduardo. Entre o "serve" e o "significa": uma análise sobre expectativas atribuídas ao esporte em projetos sociais. Licere, Belo Horizonte, v.16, n.2, p.1-33, jun.2013.

TAVARES, Ângela Ferreira; COSTA, Vera Lúcia Menezes; TUBINO, Manoel José Gomes. Recreação esportiva e seus desafios corporais no Complexo do Alemão. Motriz, Rio Claro, v.16, n.1, p.258-268, jan./mar.2010.

TUBINO, Manoel José Gomes. Estudos brasileiros sobre esporte: ênfase no esporteeducação. Maringá: Eduem, 2010.

VIANNA, José Antonio; LOVISOLO, Hugo Rodolfo. Projetos de inclusão social através do esporte: notas sobre a avaliação. Movimento, Porto Alegre, v.15, n.3, p.145-162, jul./set.2009a.

VIANNA, José Antonio; LOVISOLO, Hugo Rodolfo. Desvalorização da aprendizagem técnica na educação física: evidências e críticas. Motriz, Rio Claro, v.15, n.4, p.883-889, out./dez.2009b.

VIANNA, José Antonio; LOVISOLO, Hugo Rodolfo. A inclusão social através do esporte: a percepção dos educadores. Revista Brasileira de Educação Física e Esporte, São Paulo, v.25, n.2, p.285-96, abr./jun.2011.

ZALUAR, Alba. Cidadãos não vão ao paraíso. São Paulo: Escuta, 1994. 